\title{
aniki
}

Revista Portuguesa da Imagem em Movimento

Portuguese Journal of the Moving Image

\section{Séries de Televisão: \\ Estética, Visionamento Atento e Escrita Crítica}

Sérgio Dias Branco ${ }^{1}$

Fomos sendo persuadidos de que podemos encontrar obras de arte no grande ecrã das salas de cinema por críticos como o húngaro Béla Balázs ou o francês André Bazin. Porém, permanece a ideia de que tal não acontece, ou acontece raramente, no outro ecrã, o da televisão. Ao falar na arte da televisão, refiro-me, no contexto desta introdução, às séries de televisão. Este dossier é dedicado ao visionamento destas obras e à escrita crítica sobre elas. A temática inscreve-se, no entanto, num campo mais vasto de indagação sobre a estética da televisão que, tendo em conta a falta de desenvolvimento dos estudos televisivos em Portugal, é importante abordar num primeiro momento.

Uma discussão de recorte teórico sobre a arte da televisão deve começar com uma análise das diferenças ontológicas normalmente apontadas entre o cinema e a televisão. Como se verá, elas não são muito convincentes, mas talvez exista uma forma de distinguir a televisão do cinema que não depende da identificação de aspectos essenciais.

\section{Estética do Cinema, Estética da Televisão}

O cinema e a televisão têm sido comparados e contrastados, particularmente por John Ellis (ver 1992). Parece haver uma clivagem entre os dois, que se torna evidente quando o campo é a estética. O livro mais influente de Ellis sobre este tópico, Visible Fictions, foi publicado pela primeira vez em 1982, mas ainda é amplamente citado (ver Morley 1995; McQueen 1998, 7; Hammond \& Mazdon 2005, 9). Este estudo opta por uma abordagem essencialista que se concentra nas diferenças entre o cinema e a televisão, em vez de destacar as suas semelhanças. O seu objetivo primordial é apontar os atributos essenciais de cada meio. Ellis apresenta três pontos principais sobre a estética da televisão:

(1) a imagem é despojada, apenas com a informação visual indispensável;

\footnotetext{
${ }^{1}$ Faculdade de Letras, Universidade de Coimbra, 3000-370 Coimbra, Portugal.
} 
(2) os cortes rápidos produzem variações que captam o interesse dos telespectadores;

(3) o som fornece a maior parte da informação narrativa relevante.

Segundo ele, estas são as características centrais das imagens e dos sons da televisão. Ellis tende a considerar que todos os programas televisivos têm estes traços básicos e recorrentes. Esta é uma ideia contestável, porque a televisão produz programas diferentes, alguns deles sem propósitos artísticos (concursos de perguntas, boletins noticiosos) e, portanto, com um investimento menor em gerar interesse estético. Muitas séries de televisão contemporâneas, que têm de facto esses propósitos, desmentem que as características apontadas por Ellis sejam tão comuns. Tome-se como exemplo o primeiro episódio ("Pilot", 1.01,3/10/2004) de Donas de Casa Desesperadas (Desperate Housewives, 2004-12). A vozoff de Mary Alice (Brenda Strong) convida-nos a dar atenção à sua locução, mas também a ver aquilo a que ela se refere, já que as suas descrições são demasiado gerais. Ela descreve o dia do seu suicídio como um dia normal. Diz que preparou o pequeno almoço para a família e vemo-la trazer waffles para uma mesa com fruta, ovos, torradas, bacon, café e sumo. Diz que cumpriu as tarefas domésticas e vemo-la ligar a máquina de lavar roupa. Diz que completou os seus projetos e vemo-la pintar uma cadeira metálica de jardim. Diz que fez os recados que tinha para fazer e vemo-la levantar roupa na lavandaria. Brenda faz tudo isso de maneira descontraída, com uma firmeza que vem da repetição das mesmas atividades. A sua casa está perfeitamente limpa e arrumada - um asseio e uma ordem que admira e aprecia antes de dar um tiro na cabeça, gesto que vemos refletido na elegante moldura de uma fotografia de família (Fig. 1). Todos os pormenores que descrevi são narrativamente importantes para que se perceba o aprisionamento em que Mary Alice vive, a contradição entre a beleza da aparência e a aflição que esconde. E só é possível aceder a estes pormenores se se prestar atenção às imagens. Além disso, Donas de Casa Desesperadas é visualmente lúdica. O plano que se segue ao suicídio mostra o sumo de tomate que a sua vizinha, Martha Huber (Christine Estabrook), derramou no balcão da cozinha, evocando o sangue de Mary Alice através de um jogo de correspondências visuais (Fig. 2). 

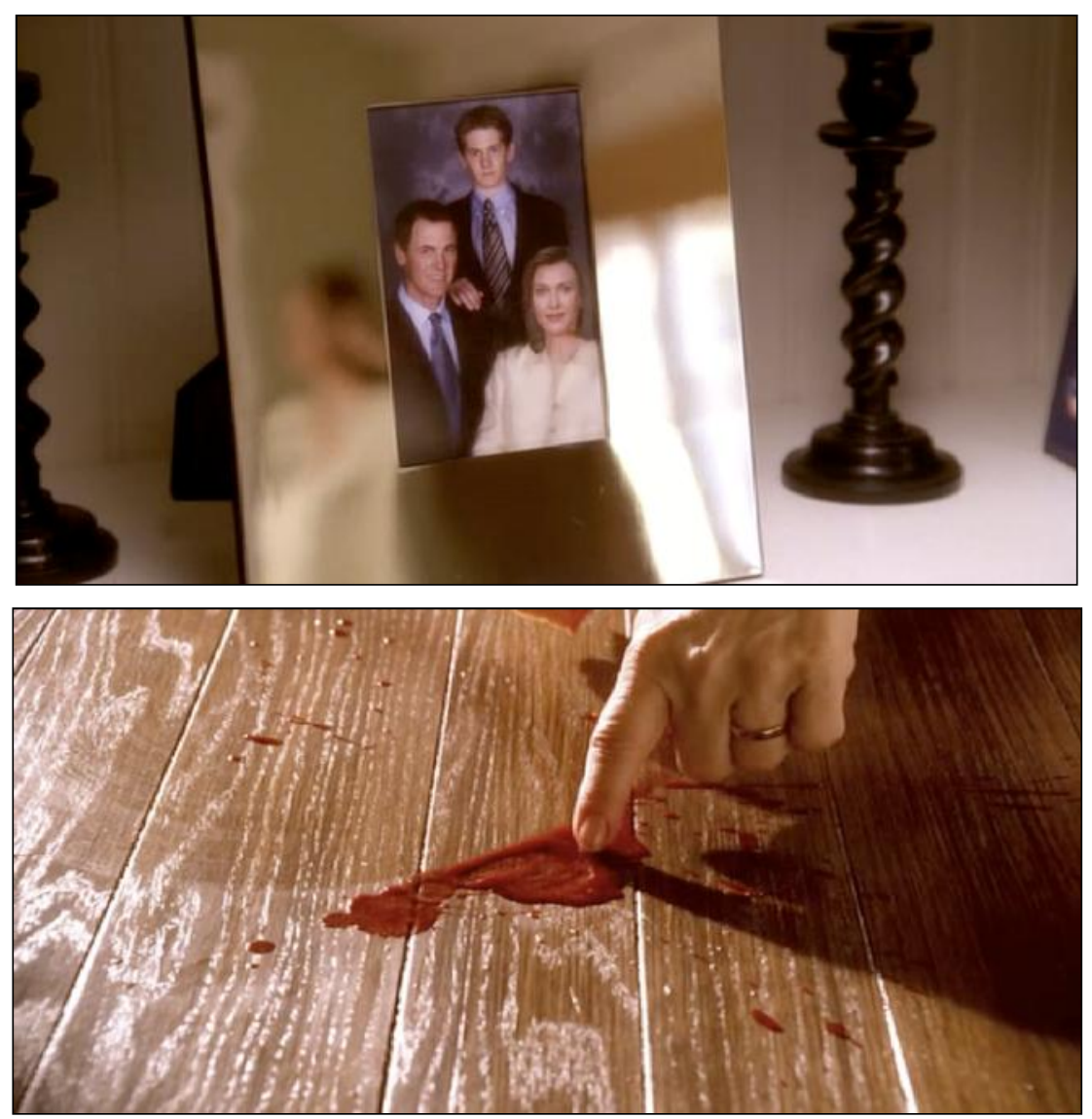

Figuras 1-2: Fotogramas de Donas de Casa Desesperadas, "Pilot” (1.01). (C) Cherry Productions \& Touchstone Television.

As ideias defendidas por Ellis resumem-se a uma tese que apresenta o cinema e a televisão como meios não apenas distintos, mas essencialmente opostos. De acordo com este argumento, as imagens do cinema são ricamente pormenorizadas, enquanto as imagens da televisão são serviçais e minimais porque, ao contrário do cinema, o som predomina sobre a imagem. Uma sequência como a de Donas de Casa Desesperadas, uma entre muitas, analisada em cima, contradiz estas ideias. De mais a mais, esta série depende também do magnetismo encenado de estrelas femininas como Eva Longoria, a primeira dona de casa desesperada que vemos na série, a fazer jogging. Não obstante, Ellis nega que elas existam na produção televisiva como existem na cinematográfica, porque à primeira faltaria o efeito fotográfico da segunda. Segundo o teórico britânico, a televisão "apresenta-se a si mesma como uma presença imediata, exceto quando toma o cinema por empréstimo com transmissões rotuladas como "filmes"' (Ellis 1992, 106; trad. minha). Esta comparação depreciativa para as obras televisivas é reveladora, já que negligencia o modo como as séries e os filmes produzem exatamente o mesmo efeito narrativo de desdobramento através do qual as atrizes têm identidades ficcionais estáveis. Karen Lury contesta da seguinte maneira a afirmação sobre a ausência de efeito fotográfico: 
O momento pró-fílmico faz tão parte da televisão como do cinema, de modo que o que é representado em duas dimensões no ecrã é também uma demonstração de que havia algo (tridimensional, sólido) lá uma vez, ou até mesmo, já que a televisão por vezes ainda é em direto, algo lá agora. (Lury 1995, 117-118)

Visible Fictions é uma publicação datada, mas tal não nos deve levar a menosprezar a importância que ainda hoje tem, nem a esquecer o seu contexto original. Durante cinquenta anos, desde a década de 1930, a televisão parecia mais ou menos estática naquilo que tinha para oferecer em termos de experiência audiovisual. Era plausível supor que as suas características permaneceriam basicamente as mesmas. Ainda assim, a discussão de Ellis não revela simplesmente aquilo que é característico da estética dos meios cinemático e televisual num período específico. Em vez disso, faz declarações gerais e amplas sobre as suas características essenciais. Analiso a seguir as questões que esta posição essencialista coloca sobre o cinema e a televisão.

\section{O Cinemático e o Televisual}

Num ensaio sobre a televisão e o cinema a partir de uma perspectiva filosófica, Noël Carroll (2003, 265-280) argumenta contra as distinções ontológicas entre as duas formas. A lista de diferenças frequentemente citadas entre uma e outra, que ele apresenta e desmente, poderia vir diretamente de Ellis, embora este autor não seja mencionado. Carroll analisa os três pontos putativos da estética da televisão já indicados, além de outros três aspectos. O primeiro é a utilização de vídeo em vez de película na produção de programas de televisão. $\mathrm{Na}$ verdade, a maioria das séries americanas contemporâneas foram filmadas em $35 \mathrm{~mm}$ e depois transferidas para vídeo até à década de 2000 e hoje são geralmente rodadas em vídeo digital de alta definição, tal como muitos filmes. O segundo aspecto é a baixa definição dos ecrãs dos televisores, uma limitação tecnológica que determinaria um correspondente baixo nível de detalhes visuais. $\mathrm{O}$ facto é que esta descrição não corresponde aos atuais televisores de alta definição, nem às tecnologias de cristais líquidos dos ecrãs planos com dimensões cada vez maiores. Finalmente, o terceiro aspecto é a persistência do relance, em vez do olhar, como a resposta corrente à televisão. Contudo, os telespectadores dedicam muita atenção a alguns programas, particularmente séries, vendo-as, revendo-as, e, em muitos casos, discutindo-as em espaços próprios para o efeito. Esta cultura de visionamento e até de discussão, que não pode ser desligada das alterações em relação aos dois aspectos anteriores, é apoiada por um olhar atento. 
John T. Caldwell desafiou esta última ideia com a noção de televisualidade (1995, 78), uma mudança na economia visual da televisão que resultou da criação de um estilo complexo e distintivo para cada série. Caldwell afirma que esta intrincada distinção visual exige uma atenção mais sustentada e concentrada. Em 2006, Ellis respondeu a este desafio, aceitando as conclusões do investigador americano, mas esclareceu que não estava a falar nos programas individuais (18). Ou seja, estaria a referir-se à experiência televisiva sem individuação dos programas, ao fluxo identificado por Raymond Williams $(1974,86)$. Se assim for, também esta resposta recente é problemática. É certo que ainda não estamos definitivamente numa era da pós-transmissão televisiva, mas a evolução da televisão tende claramente para a fragmentação da experiência através da possibilidade de selecção de programas individuais. Além do mais, Ellis contradiz-se quando mantém que a televisão induz o relance ao mesmo tempo que aceita que muitos dos seus programas estimulam o olhar.

Carroll apresenta argumentos razoáveis que contestam as distinções essenciais entre a televisão e o cinema. Refere a história de ambos os meios como um processo único de convergência de meios em direção a uma noção abrangente de imagem em movimento. Ainda assim, ao longo do texto, o filósofo continua a referir-se à televisão e ao cinema como categorias diferentes, mesmo depois de ter demonstrado não haver nada essencialmente diferente entre elas. Esta talvez não seja uma crítica que possa ser dirigida a Carroll, porque a questão que o ocupa não é o uso destas categorias. Mas a utilização é reveladora e, como se verá, permite-nos reutilizar a palavra "televisual”. Em várias passagens, ele elucida de modo eloquente por que razão expressões como "estilo cinemático" ou "estilo televisual" são teoricamente imprecisas. O que conta como cinemático, por exemplo, "é muitas vezes estilisticamente muito divergente. O realista fotográfico contará um jornal de atualidades dos Lumière como muito cinemático, enquanto um montagista não" (2006, 163; trad. minha). Este último considerará O Couraçado Potemkine (Bronenosets Potyomkin, 1925) como muito cinemático. Carroll respondia aqui a Murray Smith, que defende que esquecer o meio conduz a uma espécie de eliminativismo do meio, como se os meios não existissem e a sua diferenciação não fizesse sentido e devesse ser abandonada. Carroll faz observações perspicazes sobre a imprecisão da expressão "cinemático". De qualquer forma, tal imprecisão é historicamente sancionada porque está historicamente enraizada; daí que não seja necessário empregar a palavra como se ela apontasse para um conjunto de regras estéticas específicas do meio. Este é um dos argumentos de Smith para a duradoura utilidade de tal expressão. Conclui

que as características do meio artístico (ou da forma artística, aliás) poderiam ser julgadas como características simplesmente em virtude da tradição - isto é, como uma questão de uma prática historicamente validada [...]. Assim, a palavra "cinemático" não 
precisa de implicar algo como uma "lei" do meio a ser observada, mas pode sugerir em vez disso uma prática estilística que é imitada. (Smith 2006, 146; trad. minha)

Recuperar e repensar esta palavra, não como um substantivo (o televisual), ou a descrição de uma qualidade (o estilo televisual), mas como um adjetivo, é uma maneira de explicar a singularidade estética das séries de televisão, rejeitando o essencialismo. Trata-se de uma abordagem historicamente contingente e situada que reconhece a utilidade do termo televisual como um adjetivo vago, porque não descreve as qualidades limitadas do que conta como televisual. Em vez disso, identifica as obras criadas com determinadas estruturas estéticas, dentro de um sistema de produção e distribuição com uma história específica de desenvolvimento. Por conseguinte, é televisual aquilo que é feito para a televisão, mesmo que as suas vias de distribuição se tenham expandido, diversificado, cada vez mais com dimensões interativas. Carroll poderá vir a estar certo a longo prazo, mas essa é uma previsão que não pode fazer esquecer que ainda diferenciamos entre o cinema e a televisão como formas que têm desenvolvido diferentes possibilidades estéticas e artísticas. Como lembra Stanley Cavell, seguindo um pensamento não essencialista, tais possibilidades não são dadas à partida: são descobertas $(1979,32)$ por intermédio da criação.

Como obras televisuais, as séries de televisão têm vindo a criar formas próprias, modos seriais de organizar e articular imagens e sons. É isso que as define enquanto meio artístico no interior do meio mais alargado da televisão, se entendermos um meio como um conjunto de práticas em evolução, e não apenas como um uso específico de materiais. Uma série como Twin Peaks (1990-91; 2017), ${ }^{2}$ por exemplo, criada por David Lynch e Mark Frost, é uma obra surrealista que começou por trabalhar sobre a performatividade da soap opera ou telenovela (Fig. 3, "Zen, or the Skill to Catch a Killer", 1.3, 19/04/1990), um dos mais populares géneros televisivos herdados da rádio, e depois chegou a uma reflexão mais ampla sobre a natureza performativa da cultura americana (Fig. 4, "Case Files", 3.05, 04/06/2017). Nesse sentido, a série explora preocupações temáticas e ideias estéticas que têm sido concretizadas de outra forma na obra cinematográfica de Lynch. A convergência de meios poderá vir a apagar as fronteiras, já diluídas, entre o cinema, a televisão, e o vídeo, mas nunca apagará as suas histórias específicas. Talvez um dia se venha a dizer que Twin Peaks é aquilo a que, no passado, chamávamos obra televisual, ou mais precisamente, obra de arte televisual. 


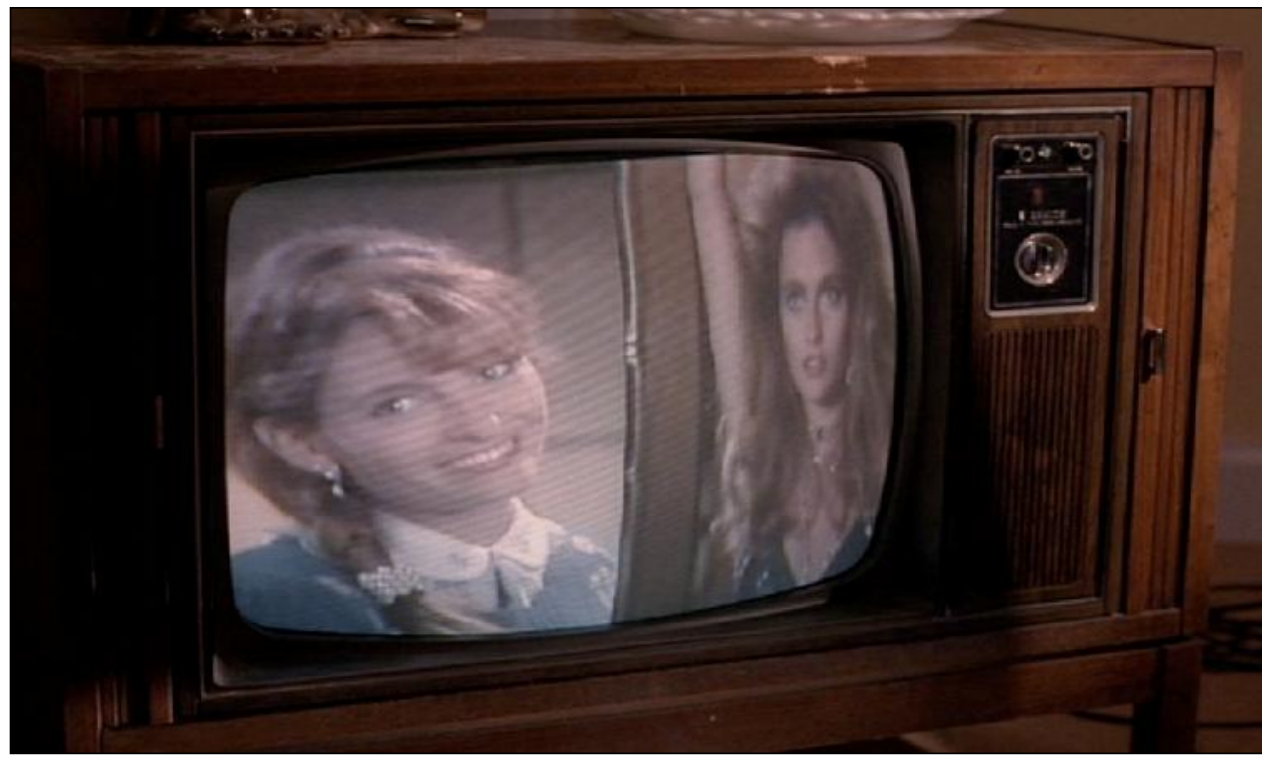

Figura 3: Fotograma de Twin Peaks, "Zen, or the Skill to Catch a Killer” (1.3). (c) Lynch/Frost Productions

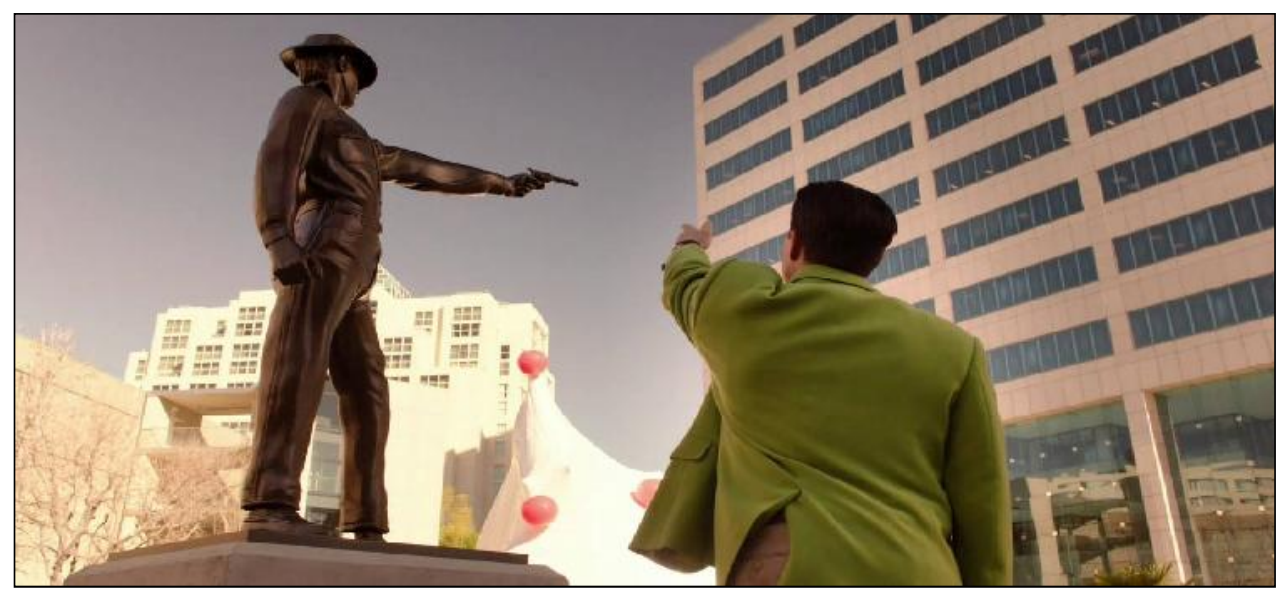

Figura 4: Fotograma de Twin Peaks, "Case Files” (3.05). (c) Lynch/Frost Productions

\section{Contributos do Dossier}

O propósito deste dossier temático foi o de recolher contributos centrados na apreciação crítica de séries de televisão. O meu entendimento da crítica de televisão ecoa o de Alex Clayton e Andrew Klevan da crítica de cinema, no volume que editaram sobre a linguagem e o estilo dessa prática (2011). Adaptando as ideias por eles desenvolvidas, pode dizer-se que a crítica de televisão é uma forma de escrita que procura apreciar e transmitir as qualidades distintivas de algumas séries televisivas. A importância da crítica decorre, assim, do modo como ela "aprofunda o nosso interesse em [séries] individuais, revela novos significados e perspectivas, expande o nosso sentido do meio artístico, confronta as nossas suposições sobre o valor e apura a nossa capacidade para discriminar" (Clayton \& Klevan 2011, 1; ênfase no original). 
Em anos recentes, surgiu um bem-vindo e crescente interesse académico pelas dimensões estéticas da ficção televisiva e pelas questões particulares de julgamento e valor que levantam (Jacobs e Peacock 2013). Apesar disso, a análise pormenorizada de séries e das suas qualidades estilísticas permanece relativamente rara nos estudos televisivos. Os desafios únicos deste tipo de escrita são igualmente pouco discutidos. Escrever sobre séries de televisão implica lidar com a sua expansividade temporal, com as suas estruturas e dinâmicas complexas (ver Mittell 2015), e com valores que não têm correspondências diretas nas tradições da crítica de cinema, literatura ou artes plásticas. Neste sentido, o dossier amplia o corpo existente de escritos críticos sobre estas obras e, ao mesmo tempo, aprofunda a nossa compreensão dos seus desafios e valores singulares.

Um princípio subjacente ao dossier é o de que a escrita crítica, apoiada no visionamento atento, permite desenvolver linhas teóricas de abordagem a estas questões metodológicas. Por conseguinte, a teoria emerge da resposta e da análise às séries de televisão. É precisamente isso que fazem os artigos que compõem o dossier. Jeferson Ferro e Fernando Torres Andacht desenvolvem uma leitura da segunda temporada de True Detective (2014-) em torno da memória e da identidade, apoiando-se em conceitos semióticos e estabelecendo paralelos com outras séries. Wanderley Anchieta e Jonas Pilz concentram-se nos excessos narrativos de Breaking Bad (2008-13) e nos efeitos interpretativos que esses pormenores estilísticos produzem, nomeadamente no âmbito das discussões entre fãs. Benjamim Picado analisa as inflexões da mise-en-scène nas séries de Aaron Sorkin, em particular em Os Homens do Presidente (The West Wing, 1999-2006), e salienta as relações de colaboração entre este criador e alguns realizadores. Milena Szafir examina o uso da montagem em Black Mirror (2011-) para além da dialética entre transparência e opacidade, destacando as operações reflexivas e criativas da composição audiovisual e o seu carácter combinatório e híbrido. Ana Cabral Martins fecha o dossier com um artigo (em inglês) que analisa Westworld (2016-) no contexto das discussões contemporâneas sobre a complexidade das séries de televisão, os quebra-cabeças narrativos, e as ligações parareferenciais.

Este conjunto de cinco ensaios comprova a riqueza intrincada das propostas estéticas das séries de televisão contemporâneas. Ao mesmo tempo, revela diferentes abordagens, bem assentes nas discussões que atualmente decorrem no campo dos estudos televisivos, ou devidamente argumentadas como leituras de obras individuais. São valiosos contributos - particularmente no contexto português, mas também no brasileiro - para o desenvolvimento dos estudos sobre estes objetos com grande impacto e influência culturais. 


\section{BIBLIOGRAFIA}

Caldwell, John T. 1995. Televisuality: Style, Crisis, and Authority in American Television. Piscataway: Rutgers University Press.

Carroll, Noël. 2003. Engaging the Moving Image. New Haven: Yale University Press.

—_- 2006. "Engaging Critics". Film Studies: An International Review 8: 161-169.

Cavell, Stanley. 1979. The World Viewed: Reflections on the Ontology of Film, ed. aumentada. Cambridge: Harvard University Press.

Clayton, Alex \& Andrew Klevan, eds. 2011. The Language and Style of Film Criticism. Londres: Routledge.

Ellis, John. 1992. Visible Fictions: Cinema Television Video, 2. ${ }^{\mathrm{a}}$ ed. Londres: Routledge.

-_- 2006. "Defining the Medium: TV Form and Aesthetics". In Tele-visions: An Introduction to Studying Television, editado por Glen Creeber, 12-19. Londres: BFI, 2006.

Hammond, Michael \& Lucy Mazdon, eds. 2005. The Contemporary Television Series. Edimburgo: Edinburgh University Press.

Jacobs, Jason \& Steven Peacock, eds. 2013. Television Aesthetics and Style. Nova Iorque: Bloomsbury.

Lury, Karen. 1995. “Television Performance: Being, Acting and 'Corpsing'”. New Formations 27: 117-18.

McQueen, David. 1998. Television: A Media Student's Guide. Londres: Hodder Arnold.

Mittel, Jason. 2015. Complex TV: The Poetics of Contemporary Television Storytelling. Nova Iorque: NYU Press.

Morley, David. 1995. "Television: Not So Much a Visual Medium, More Like Visible Object”. In Visual Culture, editado por Chris Jenks, 170-189. Londres: Routledge.

Smith, Murray. 2006. "My Dinner with Noël; or, Can We Forget the Medium?”. Film Studies: An International Review 8: 140-148.

Williams, Raymond. 1974. Television: Technology and Cultural Form. Londres: Routledge. 